\title{
Serviço Substitutivo e Hospital Psiquiátrico: Convivência e Luta
}

The alternative service and the psychiatric hospital: coexistence and struggle
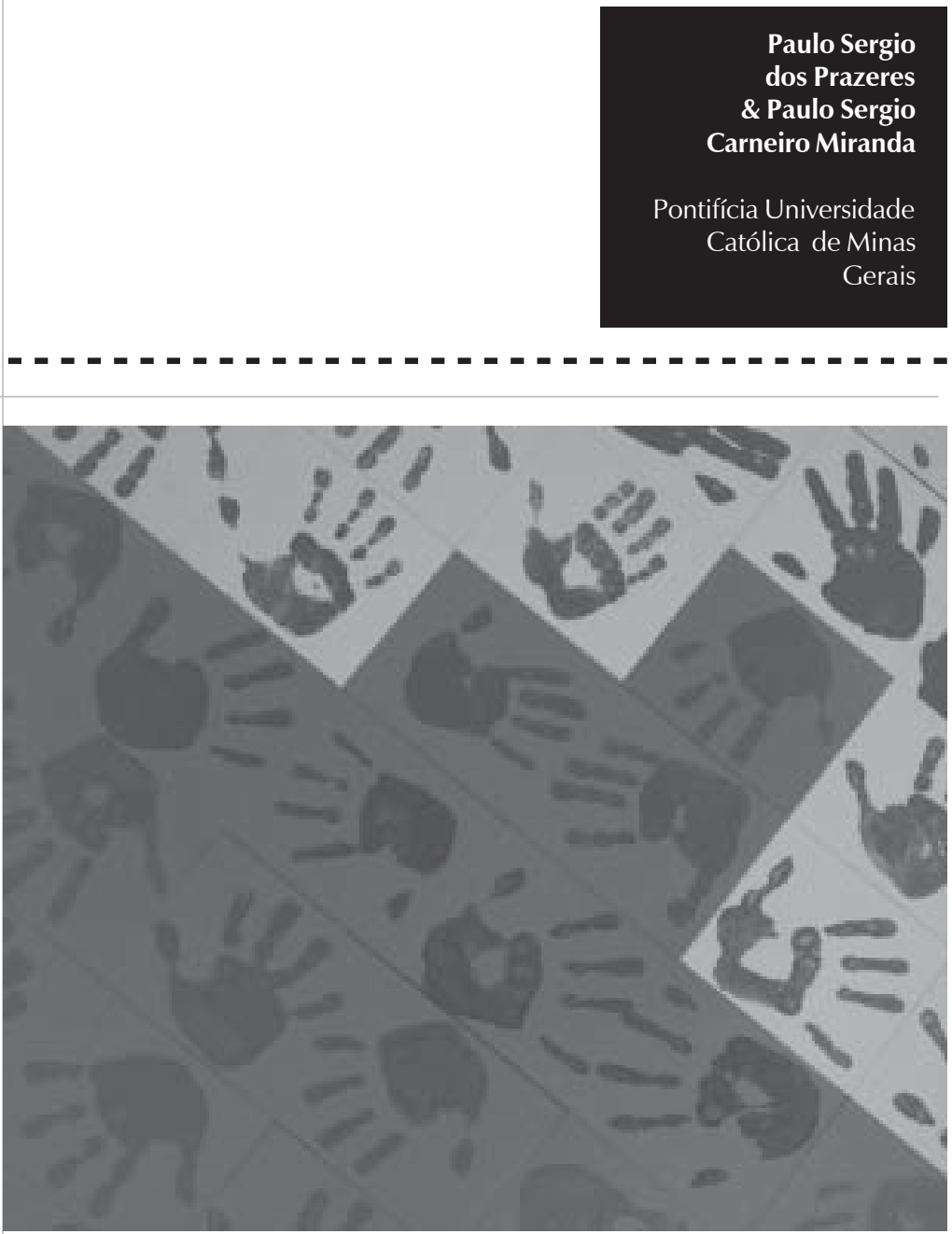


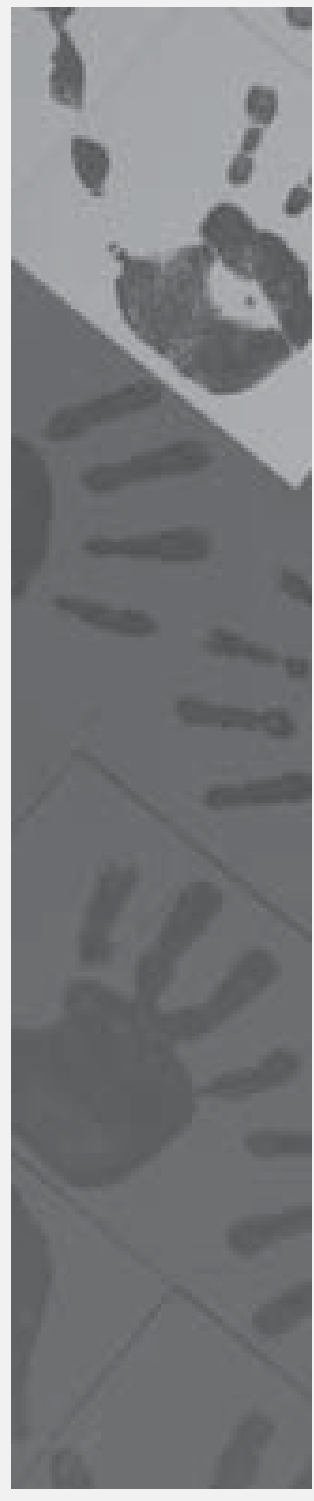

Resumo: Este artigo é um breve relato da dissertação realizada como uma das exigências para a obtenção do título de Mestre em Saúde Pública na Faculdade de Medicina da Universidade Federal de Minas Gerais (UFMG). Nela, procurou-se analisar os impasses na reforma psiquiátrica brasileira. A partir da constatação de seus avanços na oferta de serviços e na legislação bem como das dificuldades encontradas pela reforma psiquiátrica para superar o hospital, a dissertação, através de cinco hipóteses, estudou a relação entre esses dois dispositivos de tratamento. Este artigo trata da quinta hipótese, que supõe uma convivência pacífica entre os dois serviços no futuro. A pesquisa demonstrou que isso não acontece, e que a resolução dos impasses citados passa pelo avanço da reforma, por decisões políticas e pelas definições construídas com a participação dos usuários e seus familiares.

Palavras-chave: reforma psiquiátrica, luta, convivência, política.

Abstract: This paper summarizes a dissertation which was part of the requirement for the attainment of the degree of Master in Public Health at the Medical School of the Universidade Federal de Minas Gerais (UFMG). In this investigation, the impasses in the psychiatric reform in Brazil were analysed. Based on the evidences of progress both in the offer of services and in the pertaining legislation as well as on the difficulties faced in the effort to surmount the mental hospital, five hypotheses were built to study the relationship between the two modes of treatment: the alternative service and the psychiatric hospital. This paper deals with the fifth hypothesis, which posits a peaceful coexistence of the two services in the future. The investigation demonstrated that this condition has not happened until now, and the solution for the stalemates aforementioned involves the enhancement of the reform movement, political decisions and the definitions shaped by patients and their families.

Key words: psychiatric reform, struggle, coexistence, policy. 


\section{O movimento e o impasse}

Nos últimos 20 anos, o movimento da reforma psiquiátrica no Brasil tem, insistentemente, colocado para a sociedade brasileira a necessidade de se abolir o hospital psiquiátrico como local de tratamento para o portador de sofrimento mental.

Nos últimos dez anos, várias portarias e resoluções do Ministério da Saúde, leis estaduais e a Lei Federal no 10.216, de 06/ 04/2001, apontam firmemente a necessidade de que a atenção ao portador de sofrimento mental deve dar-se, prioritariamente, em serviços não hospitalares, que privilegiem a não internação do portador de sofrimento mental em hospitais psiquiátricos (Organização Mundial de Saúde - OMS, 2001, p.3).

Contudo, a política oficial brasileira não definiu o fechamento dos hospitais psiquiátricos como um ato imediato ou concomitante a essas portarias e resoluções, fazendo com que a assistência ao portador de sofrimento mental no País fique submetida a dois olhares diferentes e simultâneos:

- O modelo proposto pela reforma psiquiátrica, que supõe a produção de projetos de atenção em saúde mental orientados pelas diretrizes de superação do modelo asilar e de assunção dos direitos de cidadania.

- O modelo proposto pelo hospital psiquiátrico, que supõe a manutenção de projetos de atenção em saúde mental orientados pelas diretrizes asilares e a cassação, ainda que provisória, dos direitos de cidadania (notadamente, o de ir e vir).

A justificativa para analisar a relação entre os serviços substitutivos e os hospitais psiquiátricos baseia-se nesse impasse. Ambos tratam portadores de sofrimento mental, estão contidos no SUS (Sistema Único de Saúde), mas têm histórias distintas, principalmente no tocante às suas intervenções terapêuticas.

A radicalidade da diferença entre os dois modelos produziu grupos políticos organizados que desenvolvem ações estratégicas, agregam interesses e produzem demandas para os governos municipal, estadual e federal a fim de conseguirem respostas que, de preferência, tornem hegemônicas suas teses e suas ações.

A reflexão proposta aqui, sobre a relação entre o serviço substitutivo e o hospital psiquiátrico, busca contribuir com a produção acadêmica sobre a discussão política e as estratégias de operacionalização (de instalação do novo modelo/manutenção do que já existia) da assistência em saúde e em saúde mental no Brasil.

O estudo teve, ainda, a finalidade de construir conhecimentos sobre o processo de instalação de um serviço substitutivo em um território em que houvesse um hospital psiquiátrico. Isso nos permitiu saber se essa instalação constituiuse em um instrumento favorável ao avanço da reforma psiquiátrica brasileira, se leva a modificações e ao enfraquecimento do hospital psiquiátrico neste território ou se, com o passar do tempo, os dois serviços passam a ter uma convivência/coexistência pacífica.

Assim, a pesquisa objetivou analisar a relação serviço substitutivo/hospital psiquiátrico na evolução histórica da reforma psiquiátrica brasileira através de cinco hipóteses:

- A instalação dos serviços substitutivos relativiza o hospital psiquiátrico como dispositivo de tratamento ao portador de sofrimento mental. 
As articulações com a sociedade local são mais determinantes para a sustentação dos dispositivos assistenciais em saúde mental do que as regulamentações do setor.

A existência do serviço substitutivo não garante a superação do hospital psiquiátrico.

As estratégias de luta do movimento da reforma psiquiátrica brasileira são semelhantes às estratégias de luta do movimento de manutenção do hospital psiquiátrico.

Caminha-se, na prática, para uma convivência pacífica entre o serviço substitutivo e o hospital psiquiátrico, ao contrário do proposto pelo script da reforma psiquiátrica, que defende a superação do hospital como dispositivo de tratamento.

Neste artigo, escolhemos, em função da exigüidade do espaço de publicação, abordar a última hipótese, pois ela é a hipótese que condensa todas as outras e que propõe a interrogação sobre o futuro da reforma psiquiátrica na cidade estudada.

\section{Metodologia}

Neste trabalho, o referencial teórico foi o materialismo histórico-dialético e o método usado foi o qualitativo. Os instrumentos foram a entrevista semi-estruturada e investigação documental. Optou-se por realizar um estudo de caso

\section{Sujeitos, campo e período de estudo}

Numa cidade de porte médio do interior de Minas, com aproximadamente 200.000 habitantes, foram entrevistados 9(nove) atores sociais qualificados em relação ao tema, que foram identificados da seguinte maneira: familiares $(\mathrm{F})$, usuários $(\mathrm{U})$, profissionais $(\mathrm{P})$, acadêmico( $(\mathrm{A})$ e gestores $(\mathrm{G})$, acompanhados de um número natural, a fim de diferenciá-los.O período abordado no estudo foi de 1996 a 2004.
A apresentação dos resultados segue uma forma que facilita a leitura e a compreensão dos mesmos: fazemos uma breve introdução, que justifica e situa historicamente o aparecimento da hipótese. Subseqüentemente, os temas abordados no estudo são trabalhados e evidenciados nas falas dos informantes. Por fim, após a apresentação dos dados, acrescentamos a discussão dos resultados e as conclusões do estudo da hipótese.

\section{Introdução à hipótese: da guerra feudal à análise estrutural}

Pretendemos verificar, aqui, a possibilidade de superação do hospital psiquiátrico a partir do estudo da convivência entre ele e o serviço substitutivo.

Sabemos que, dentre as estratégias de superação do hospital, a instalação de serviços substitutivos foi uma delas. Para Campos II (2002), a luta dos defensores do fim do hospital psiquiátrico com os que defendem sua manutenção segue um modelo feudal. Os hospitais são cercados por novos serviços e modos de assistência, com a finalidade de estrangular o hospital, mas, até que isso aconteça, pode-se gastar um século, um século e meio.

Essa forma de luta provoca questões sobre condições políticas, culturais, técnicas, de recursos humanos, de participação popular e financeira, dentre tantas, para que se possa dar prosseguimento à reforma psiquiátrica. Sabe-se que as condições regulamentadoras estão favoráveis ao trabalho proposto pela reforma, mas não deixam de contemplar, em seu interior, a presença do hospital psiquiátrico. Assim, não podemos escapar das seguintes constatações: a)o hospital psiquiátrico é um dispositivo assistencial presente na rede de assistência em saúde
As articulações com a sociedade local são mais determinantes para a sustentação dos dispositivos assistenciais em saúde mental do que as regulamentações do setor. 
Toda vez que alguém chega com uma nova

idéia, os mais antigos ficam meio ressabiados. Então, a própria direção do hospital

psiquiátrico, no início, recebeu o serviço substitutivo com certas

reservas, e eu percebo que hoje não tem mais isso. Mas eu acho isso natural (P2). mental no Brasil e b) inversamente, o País já conta com uma rede de serviços substitutivos razoável, que estabelece cotidianamente sua tradição (de luta pela construção de um espaço mais solidário, mais democrático que o hospital psiquiátrico, que suporte a diferença e que "lide com o louco permitindo que ele seja louco", conforme nos disse um dos entrevistados).

Os serviços substitutivos e o hospital psiquiátrico têm várias características semelhantes, das quais destacamos, aqui, o fato de ambas cuidarem de portadores de sofrimento mental grave. Abordar o problema considerando a semelhança entre os dois permite-nos estudar um sistema de relações que não aparece imediatamente ou muito claramente entre eles.

Essa semelhança permite-nos estudar o serviço substitutivo e o hospital psiquiátrico tomando uma atitude estruturalista, posto que podemos considerá-la a condição que submete os dois serviços a um mesmo princípio. Para Joël Dor (1989, p. 22), esse princípio gera relações entre os elementos da estrutura (no nosso caso, o serviço substitutivo e o hospital psiquiátrico), que são nada mais, nada menos que leis estabelecidas entre os objetos ou seus elementos e que podem evidenciar propriedades de uma certa ordenação entre eles.

\section{Resultados: que convívio é esse?}

Com essa hipótese, pretendemos estudar o futuro do relacionamento entre o hospital psiquiátrico e o serviço substitutivo. Estudar esse relacionamento é estudar o relacionamento entre o velho e o novo, o instituído e o instituinte, enfim, a relação entre opostos. Nas entrevistas, vimos que, desde o aparecimento do serviço substitutivo na cidade em questão, essa relação foi marcada pelo confronto e pelas afirmações de diferenças entre ele e o hospital psiquiátrico .

Toda vez que alguém chega com uma nova idéia, os mais antigos ficam meio ressabiados. Então, a própria direção do hospital psiquiátrico, no início, recebeu o serviço substitutivo com certas reservas, e eu percebo que hoje não tem mais isso. Mas eu acho isso natural (P2).

Os entrevistados classificaram esses antagonismos como diferenças de interesses e propostas.

Os interesses de determinado grupo são bem diferentes dos interesses do outro grupo. Por exemplo, era nítida a dificuldade; a proposta do sistema público instituído em Divinópolis era muito diferente dos interesses da proposta do prestador de serviços.

Esses antagonismos trazem, como conseqüência, a interpretação que a sociedade local faz do papel de cada serviço na cidade e, conseqüentemente, da relação entre os dois serviços de saúde mental.

As pessoas não entendem qual é a função do hospital psiquiátrico, o que é o papel dele, o que é o papel do serviço substitutivo, não. Eu acho que o hospital contribuiu muito pra isso (G4).

Por outro lado, para um outro entrevistado, esse mesmo antagonismo ocorre porque o serviço substitutivo estabelece uma relação de desconfiança em relação ao hospital psiquiátrico.

É um dever da equipe. Então assim, quando eu falo do hospital, é porque eu sei que o hospital tenta desestruturar isso aí, e a gente tem que ficar vigilante (G4).

Após, encontramos um grande bloco de afirmações sobre a relação vista sob a ótica 
da gestão do sistema de saúde do município. Segundo os entrevistados, o hospital se submete às regras do SUS, e essas regras são uma intervenção sobre ele, o que causa resistência e a percepção, pelo hospital, de que elas são o prenúncio do seu fim. $\mathrm{O}$ hospital percebe essa intervenção como um projeto de sua exclusão do sistema de saúde no município.

Pra mim está claro isso, o projeto da exclusão (do hospital psiquiátrico), que é uma bobagem, na minha concepção. Talvez só vão mudar a placa de lugar, e é isso que nós vamos ver um dia, só vão mudar a placa de lugar [...] (P2).

Um terceiro aspecto da relação é o da continuidade de tratamento dos usuários dentro do sistema de saúde do município. Ela é vista como a possibilidade de uma convivência mais amena entre os dois serviços, mas, apesar disso, esbarra em um problema importante: a presença do serviço substitutivo no município não foi suficiente para definir a organização do sistema de saúde local no tocante a um serviço ser complementar ao outro.

Eu gostaria que não houvesse, mas ainda há, uma relação, na medida em que o serviço substitutivo ainda não pode substituir o hospital. (Esta relação é) De completar. Porque na realidade...Quem complementa quem? Eu acho que o hospital complementa o serviço (G4).

Em meio a tudo isso, os familiares se posicionam considerando que, se há algo a ser continuado, é o tratamento utilizado no hospital psiquiátrico após as altas das internações, o que significa uma melhora na integração entre os serviços:

[...] eu vi agora uma família que participa do nosso grupo que o paciente está tomando um remédio de última geração, o famoso XYZ. Então, saiu do hospital com o aconselhamento do remédio, foi pro serviço e o psiquiatra do serviço manteve o XYZ e melhorou muito o paciente. Então, eu acho que melhorou essa integração (F1).

Um quarto aspecto é o do papel dos profissionais na relação. Esse papel é estratégico, e os usuários são influenciados pela percepção que os profissionais têm de qualquer um dos elementos que dela fazem parte. Nas entrevistas, destaca-se a influência dos familiares pela percepção que os profissionais do hospital psiquiátrico têm do serviço substitutivo.

Aquela passeata (feita na cidade por familiares de portadores de sofrimento mental, contrária à instalação da porta-deentrada para o hospital psiquiátrico no serviço substitutivo)...a motivação foi mais do hospital, porque, com a dificuldade da internação, o hospital podia diminuir o seu trabalho, dispensar funcionários. Então, partiu deles, nem foi da direção, viu, nem foi da direção. Eles entenderam logo que poderiam perder os seus empregos e fizeram aquela passeata (U1).

Há também uma percepção do outro serviço pelo profissional que depende da história de sua relação particular com os serviços, notadamente pela história de vida dos profissionais que trabalharam no hospital psiquiátrico e migraram para o serviço substitutivo.

E acabou que isso (o fato de o profissional ter trabalhado no hospital e hoje estar no serviço substitutivo) se refletiu na relação hospital psiquiátrico-serviço e não era para refletir, não tem nenhum sentido isso. Acho que as pessoas não souberam separar muito 
o pessoal do serviço de saúde, quer dizer, os pacientes não têm nada a ver com essas brigas (P2).

Uma outra determinação da relação entre os dois serviços ocorre quando a relação entre os profissionais é tomada como a relação entre os serviços e, também, quando o contrário acontece: a relação entre os serviços é tomada como a relação entre os profissionais. Não, ela não é do usuário, de jeito nenhum...É como se tivesse pessoalizado as instituições... Existe uma coisa que não dá pra entender, as pessoas não vêem que são instituições; então, existe essa personificação das instituições (P1).

Um último aspecto apontado pelas entrevistas foi o da perspectiva de futuro da relação entre os serviços. Inicialmente, essa perspectiva é pensada pela concepção de que o hospital tem que aceitar a organização hierarquizada do sistema de saúde mental na cidade.

Que tivesse a contra-referência pro serviço substitutivo nos casos de internação, independente do dinheiro que a pessoa tem...Que tivesse essa contra-referência, que as pessoas pudessem fazer o tratamento ambulatorial aqui no serviço, e que a internação fosse efetivada, já que o hospital existe, já que o serviço não é 24 horas, porque se fosse 24 horas não precisaria disso, e a pessoa seria internada realmente quando precisasse (P1).

Na seqüência, a relação é pensada pela via do trabalho conjunto entre os dois e pelo estabelecimento de uma relação que seja pautada pela autonomia das ações e respeito entre os serviços.

Eu não sei nem se eu sou a favor da convivência muito pacífica (risos) eu não sei nem se sou a favor disso. Mas eu acho que uma relação mais respeitosa, eu acho que muito pacífico passa pra passivo e vira uma coisa horrorosa (P2).

Para outros entrevistados, deve-se criar mediadores na relação entre os dois serviços, posto que a capacidade de luta entre os dois tem limites.

[...] Eu acho que quando a gente está forçando a vertente do substitutivo e criando quase que uma trincheira, uma luta, uma guerra, de um lado o aberto, de outro lado, o supostamente fechado, eu acho que isso pode ter um certo limite. Eu acho que a gente tem que perceber o que há nas instituições de aberto e de fechado, pra daí a pouco a gente tentar ter uma maturidade mais cristalina, mais sólida sobre o que é um serviço de fato substitutivo, que vai nesse caso, nessa cidade, vai coexistir no mesmo território, na mesma cidade com um serviço fechado... Eu acho que são especificidades, que, numa pesquisa como essa, têm que ser pensadas. Então, eu acho que a gente tem que buscar mediadores nisso (A1).

\section{Discussão: convivência e repetição}

Propusemo-nos, aqui, a interrogar sobre o futuro da relação entre o serviço substitutivo e o hospital psiquiátrico da cidade estudada. Essa relação se dá entre dois serviços de saúde antagônicos, com propostas absolutamente diferentes, através das quais a construção de um sistema está em pauta.

A pergunta feita, aqui, é sobre o problema posto ao País pela reforma psiquiátrica: como convivem serviços substitutivos e hospitais psiquiátricos, símbolos do modelo que se quer construir e do modelo que já está construído e instalado no País?

Acreditamos que uma atitude estruturalista para a interpretação dessa convivência, como 
já dissemos anteriormente, deve ser usada aqui. O sistema de saúde mental municipal rearranja-se a cada movimento de um de seus membros (o hospital ou o serviço substitutivo), um modificando a posição do outro, numa dança constante que afeta a todos os envolvidos na questão, sejam gestores, usuários ou profissionais.

Nas entrevistas, vimos que a convivência entre o serviço substitutivo e o hospital psiquiátrico, desde a fundação do primeiro, foi marcada pelo confronto. Historicamente, sabemos o lugar ocupado pelos hospitais psiquiátricos no Brasil: centrais e únicos no sistema de saúde mental até o final da década de 1980, consumidores da quase totalidade de recursos financeiros para a assistência aos portadores de sofrimento mental da Previdência Social e ligadas às formas de repressão do poder político instituído no mundo todo - o que fez, de acordo com Bertolote(1995), a ONU(Organização das Nações Unidas) discutir sua função social no Planeta e apoiar os debates sobre sua extinção. A marca principal dos hospitais psiquiátricos tem sido a posse do poder, inclusive do ponto de vista do conhecimento.

As entrevistas 'captam', na cidade, uma repetição dessa posição histórica dos hospitais psiquiátricos, seja pela dificuldade em referenciar os usuários para o serviço substitutivo seja para acatar as normatizações do SUS local. Isso nos permite supor que o hospital local deseja manter-se na posição que historicamente construiu.

Basaglia (1985, p.101) descreve o funcionamento do hospital psiquiátrico como "uma nítida relação entre os que têm e os que não têm poder", mostrando o quanto essa forma de relação determina como os profissionais irão lidar com os portadores de sofrimento mental. Para ele, o profissional se tornou o agente executor dessa relação, tornando-se aquele que põe em prática a exclusão do portador de sofrimento mental em função dessa relação de poder.

O serviço substitutivo é um dispositivo de atenção em saúde mental que significa, entre outras coisas, a possibilidade de se cuidar do portador de sofrimento mental sem retirá-lo totalmente de seu meio, bem como a facilidade maior do mesmo no acesso ao hospital psiquiátrico, principalmente a partir do momento em que este passou a ser a porta de entrada para internações hospitalares. Portanto, o serviço e o hospital fazem parte de um sistema cuja finalidade é a assistência ao portador de sofrimento mental.

Entretanto, o hospital desejar manter-se na mesma posição que teve ao longo dos anos anteriores à década de 1990 é desconhecer essa possibilidade, essa facilidade e o próprio sistema instalado no município. Fica evidente que a relação do hospital com o serviço substitutivo revela-se "colada" à terapêutica proposta por ele aos portadores de sofrimento mental, ou seja, o serviço pode fazer parte da possibilidade de sua abordagem terapêutica bem como o hospital pode fazer parte da abordagem terapêutica do serviço substitutivo.No entanto, Basaglia (1985) fez a seguinte observação:

A situação (a possibilidade de uma abordagem terapêutica do doente mental) se revela intimamente ligada e dependente do sistema, onde toda relação está rigidamente determinada por leis econômicas. Ou seja, não é a ideologia médica que estabelece ou induz um ou outro tipo de abordagem, mas, antes, o sistema socio-econômico é que determina as modalidades adotadas em níveis diversos (1985, p. 105). 
A partir desse ponto, podemos entender porque o serviço aberto estabelece uma relação de desconfiança com o hospital. As determinações históricas de fundação desse serviço são feitas em outras bases: elas se deram a partir do questionamento do papel dos hospitais psiquiátricos, de suas sustentações teóricas e da necessária mudança de postura do poder público em relação a eles. Isso ocorreu porque os movimentos sociais que geraram as propostas da reforma sanitária e da reforma psiquiátrica deram ao Estado brasileiro(seja no municipal, estadual ou federal) e aos serviços instalados por ele a função, dentre outras, de prover, para o portador de sofrimento mental, uma assistência extra-hospitalar e de ser o controlador e avaliador dos hospitais psiquiátricos (MS, 2004).

Nos parágrafos anteriores, trabalhamos com a noção de sistema sem discutir o problema da continuidade de tratamento na cidade, continuidade significando, aqui, o que é feito com o usuário após sua passagem pelo hospital psiquiátrico ou após sua passagem pelo serviço substitutivo. Na perspectiva assistencial, quem complementa quem, nesse sistema? O serviço complementa o hospital ou vice-versa? Obviamente, os dois serviços têm posições antagônicas em relação a essa questão, já que eles disputam poder.

Mas por que estamos falando de complementariedade do tratamento, complementariedade de serviços? Há algumas razões. Entre elas, parece-nos que a mais importante é o fator de cronicidade da doença. Considerar esse fator faz com que entendamos que a possibilidade de tratamento de um portador de sofrimento mental vai além de um serviço e além de um único ato terapêutico. Cuidar de um portador de sofrimento mental supõe a hipótese de que, a partir do primeiro ato terapêutico, ele sempre retorne para receber outro e mais outros.
Há uma persistência da cronicidade, o que faz com que apenas esses dois serviços não sejam suficientes para combatê-la. Como seria possível supor o cuidado integral de um portador de sofrimento mental através de dois únicos serviços, com seus espaços bem delimitados e com uma interação difícil em função, por exemplo, da disputa de poder e das dificuldades de gestão? A questão da continuidade de tratamento traz, ao centro da discussão, o tema do seu objetivo. A que nos prestamos ao introduzir o portador de saúde mental numa rede de cuidados do SUS? O que os instrumentos de tratar nos oferecem para que eles possam caminhar nessa rede ou nesse sistema?

A outra razão seria a da própria organização do sistema. A organização formal da rede de saúde mental da cidade tem o seguinte fluxo para o paciente: ela supõe um crescente nível de complexidade assistencial do centro de saúde até o hospital psiquiátrico, passando pelo serviço substitutivo. É uma organização de fácil entendimento, contudo, de difícil implementação, pois sabemos que ela não esgota as necessidades de recursos para atender o portador de sofrimento mental.

Além disso, ela é de difícil gestão. Uma organização de saúde que contemple serviços hierarquizados necessita de uma gestão muito refinada e competente, que permita e facilite o fluxo dos pacientes dentro dela. A pergunta "Quem complementa quem?", encontrada nas entrevistas, denuncia falhas na gestão bem como uma possível obscuridade quanto aos papéis dos serviços e da política que se quer implementar. Claro está que os serviços não são passivos em relação a essa problemática, especialmente o hospital psiquiátrico, conforme demonstrado anteriormente, em função de cada vez mais adotar práticas do serviço substitutivo em seus procedimentos terapêuticos. 
A discussão sobre a continuidade do tratamento impõe-nos a relativização dessa pergunta. Ora, se pensarmos com a cabeça do serviço substitutivo, o complemento é o hospital psiquiátrico, mas, se pensarmos com a cabeça do hospital, o complemento é o serviço. Contudo, para os familiares dos portadores de sofrimento mental, após a internação, o que importa é o serviço aberto continuar o tratamento do hospital psiquiátrico, mantendo o paciente com o mesmo medicamento e com as mesmas ações terapêuticas. Essa postura dos familiares pode não estar em consonância com a postura dos usuários, mas oferece-nos um fragmento de avaliação do serviço substitutivo e indicanos que os familiares estão falando mais da capacidade resolutiva do serviço substitutivo no tocante à remissão de sintomas e quem sabe até de adequação do usuário ao padrão normal de comportamento. Bertolote (1995, p.154) afirmou que o "mais importante, para os usuários, é a qualidade dos serviços prestados, respeito aos seus direitos, a melhoria da qualidade de suas vidas e não apenas o local onde os cuidados são prestados". Para Ornelas (2001, p. 61), após tentar cuidar de seus familiares sozinha e ter muito sofrimento com essa tentativa, aceitar o hospital psiquiátrico significava a aceitação de um lugar "onde, pelo menos, havia algum profissional oferecendo alguma forma de tratamento e, principalmente, dividindo o cuidado." Assim, fica evidente que, aos familiares, importa a resolutividade dos serviços, ainda que essa resolutividade não vá além do reconhecimento da divisão do sofrimento com outras pessoas, estejam os usuários onde estiverem.

Logicamente, as questões colocadas pelos familiares mostram-nos que a referência e a contra-referência interserviços não deve ser tomada meramente do ponto de vista objetivo da gestão. Há que reconhecer a necessidade de estudarmos os aspectos da aceitabilidade de um serviço de saúde mental, mas estudos conseqüentes, supomos, só podem ser feitos se considerarmos a palavra dos recebedores dos cuidados oferecidos pelos dispositivos em saúde mental, ou seja, os familiares e os portadores de sofrimento mental. Essa discussão remete-nos à necessidade imperativa levantada por Basaglia (1985) de colocarmos o conhecimento, os serviços e, no caso em tela, o sistema hierarquizado de saúde mental em suspenso para fazer aparecer, nas discussões, o sujeito de que se cuida.

Um quarto aspecto sobre o estudo da convivência entre os serviços é o do papel dos profissionais nessa relação. Os profissionais têm um papel relevante no processo de reforma psiquiátrica e, portanto, numa reforma como a brasileira, que vem sendo feita sem a necessária prescindência do hospital psiquiátrico, eles têm um importante papel na relação entre o serviço substitutivo e o hospital psiquiátrico.

Nas entrevistas, a influência dos profissionais sobre os familiares na avaliação dos serviços, a relação que cada profissional tem com o serviço em que trabalha bem como as histórias particulares de cada profissional com o serviço aberto ou com o hospital psiquiátrico são importantes na descrição da relação entre os serviços. As entrevistas nos mostram que há uma tendência dos profissionais a fazerem uma 'confusão' entre suas relações pessoais e a relação entre os serviços, no sentido de que disputas particulares no município por espaço e poder sejam levadas e utilizadas por eles nos serviços como se fossem disputas pelo projeto político local. Inversamente, há também a prática de se tomarem as diretrizes da política como questões pessoais, o que tem, como conseqüência, um acirramento nas dificuldades da relação entre os dois serviços.

Essas posições dos profissionais sobre os serviços denunciam as dificuldades para os 
profissionais participarem da reforma onde estiverem, no hospital psiquiátrico ou no serviço aberto. A reforma psiquiátrica é um empreendimento de muito custo pessoal e profissional. Para Desviat (1999, p. 80):

O fechamento dos hospitais psiquiátricos se converteu em um empreendimento árduo e arriscado, política e profissionalmente, para aqueles que assumem essa responsabilidade, não apenas pelas dificuldades técnicas e pela tremenda mobilização de recursos humanos e materiais que ele pressupõe, mas também, acima de tudo, pela oposição trabalhista e sindical fundamentada na possível diminuição de empregos, pelo medo da mudança e da perda do papel e do poder pelos profissionais, nisso se incluindo médicos e psicólogos [...]. A partir do que vimos, aqui, sobre o processo de reforma na cidade, cuja meta de superação do hospital psiquiátrico está colocada como uma possibilidade, pode-se perceber que as preocupações de Desviat (1999) sobre as situações a que são submetidos os profissionais são pertinentes à realidade local. Basta lembrarmos que, segundo um dos entrevistados, uma das estratégias do hospital psiquiátrico local para enfrentar a reforma psiquiátrica, a passeata contra a instalação da porta de entrada no serviço aberto, foi executada pelos seus trabalhadores.

Gostaríamos de acrescentar mais uma observação sobre a participação dos profissionais na relação entre os serviços. $\mathrm{O}$ fato é que mudanças na assistência puseram o saber do hospital psiquiátrico em suspeita, seja pelo questionamento dos efeitos que a dominação prescrita pela psiquiatria aos portadores de sofrimento mental tem sobre os trabalhadores de saúde mental, não lhes oferecendo saídas mais autônomas no cuidado com o portador de sofrimento mental (Basaglia, 1985, p. 103), seja pelos efeitos da reforma sanitária, que supõe a autonomia e a participação dos usuários no controle e na gestão do SUS. A reforma psiquiátrica e o
SUS apontam uma saída para a relação tumultuada entre os profissionais dos dois serviços: a consideração de um sistema que pressuponha a submissão dos dois serviços a uma gestão única e a necessária participação dos usuários na construção de parâmetros para a assistência, atuando como intermediadores de relações entre aqueles que deles devem cuidar. Vasconcelos (2001) apresenta essa proposta quando afirma, a partir da defesa do princípio da participação popular no SUS, a necessidade de participação dos usuários na gestão do sistema.

Na parte final dos resultados apresentados, os entrevistados discutiram o futuro da relação entre os dois serviços. A primeira perspectiva desse futuro é a da aceitação, pelo hospital, das normas de hierarquização dos serviços, sendo destinado a ele o nível terciário da assistência. Essa postura supõe a hierarquização dos serviços por níveis de complexidade e deve ser operacionalizada através da referência e contra-referência entre o hospital psiquiátrico e o serviço substitutivo (conforme é proposto hoje, mas não é realizado). Essa forma de organização de serviços é derivada da leitura feita por setores da reforma sanitária que colocam na gestão do sistema a ênfase na sua hierarquização assistencial.

Essa forma de organização de serviços pode ser razoável, mas não corresponde à realidade cotidiana do trabalho em saúde mental. Os serviços substitutivos, notadamente os CAPSs (Centros de Atenção Psicossocial), não se diferenciam do hospital psiquiátrico quanto à gravidade dos casos ou procedimentos estabelecidos. Um caso de um portador de sofrimento mental que é atendido no hospital é passível de ser cuidado numa estrutura como a do serviço substitutivo. Toda a tecnologia é a mesma, só não o são: a disponibilidade de horário para o acolhimento do portador de sofrimento mental (o serviço 
aberto não funciona diuturnamente) e o objetivo do tratamento. Essa indiferenciação, construída ao longo desses anos da reforma psiquiátrica, aponta uma forma muito consistente de flexibilização da oferta de assistência em saúde mental, com consideração de parcerias intersetoriais no cuidado ao usuário e a utilização de todos os recursos da saúde como locais de provável assistência em saúde mental. Isso tem sido feito nos centros de convivência, nos hospitais gerais, nos PSFs (Programas de Saúde da Família), nos centros de saúde, nos espaços das ONGs (organizações não governamentais), nos grupos de auto-ajuda, etc. Resta cuidar dos enfrentamentos de poder e adequação do hospital psiquiátrico a normas de gestão, caso a definição do modelo se mantenha como é hoje, hierarquizado com o hospital na função de retaguarda para o serviço substitutivo.

Nos resultados, vimos também que uma possibilidade de futuro da relação entre os dois serviços é a do trabalho em conjunto. Essa possibilidade de futuro supõe uma articulação bem integrada dos serviços, com a estipulação de metas e objetivos comuns. No Brasil, uma experiência de referência dessa forma de atuação é a do hospital Cândido da Silveira, de Campinas, São Paulo. Há doze anos, dentro desse hospital, está sendo construído seu esvaziamento com ações articuladas de saúde mental na rede de saúde extra-hospitalar da cidade. Recentemente, o município fez novos investimentos em saúde mental alocando recursos humanos e esforços na inclusão da mesma no PSF (Campos I., 2001).

Após a proposição de ações conjuntas, os entrevistados destacam que o papel dos profissionais é fundamental na construção de um futuro que contemple o trabalho dos dois serviços de uma forma sistemática. Essa superação somente é possível se eles superarem as divergências pessoais mútuas. De qualquer forma, um futuro pensado assim depende do estabelecimento de treinamentos e discussões conjuntas bem como do estabelecimento de metas e objetivos comuns. Essa é uma decisão do campo da política, e acreditamos que não seja sustentável que o trabalho conjunto entre o hospital e o serviço substitutivo seja colocado como dependente das posições individuais dos trabalhadores. Passos (2001, p.13), ao discutir o setor 59G21 francês, na conclusão do seu artigo, afirma que:

O processo francês parece caracterizar-se por grande centralização e planificação pelo Estado, grande cobertura do território nacional e boa qualidade na prestação de serviços. Por outro lado, dada a recusa dos atores em enfrentar dimensões políticas do processo, não se conseguiu romper com a pesada estrutura hospitalar (centro de emanação das políticas), construir um modelo comunitário, como pretendia a política de setor, nem se fazer frente à enorme expansão da psiquiatria privada e do tecnicismo biologizante.

Finalmente, localizamos, nas entrevistas, a necessidade de que se criem mediadores da relação entre os dois serviços a fim de que o contato entre os mesmos seja possível, já que a capacidade de luta entre eles tende a um esgotamento. Essa proposta parece querer afastar do debate o perigo e acalmar o novo que possa aparecer do embate entre os dois modelos que os serviços representam. $\mathrm{O}$ perigo é se fazer com que várias posições cristalizadas pelos atores atuantes em saúde mental sejam trocadas por novas, que, enfim, definam o rumo da reforma psiquiátrica brasileira. Essa reforma indica-nos a criação de novos dispositivos para a solução do impasse em que se encontra o avanço dos serviços. Parece-nos que há, na reforma, um reconhecimento de que o avanço possível em saúde mental não está do lado do hospital psiquiátrico. Ele está do lado das estruturas 
...se o hospital psiquiátrico resolver a questão da liberdade, ele vira um serviço substitutivo. extra-hospitalares, pois o avanço do hospital psiquiátrico vai sempre ser barrado pela questão da liberdade. Parafraseando um dos entrevistados desta pesquisa, que dizia: "se o serviço substitutivo tiver funcionamento vinte e quatro horas, ele vira hospital psiquiátrico", afirmamos que: se o hospital psiquiátrico resolver a questão da liberdade, ele vira um serviço substitutivo.

\section{Conclusão: escapar da repetição}

Concluindo, as discussões feitas aqui sugerem que o processo político irá definir a convivência entre os dois serviços. Contudo, as condições políticas, técnicas, culturais, de orçamento, de participação popular, enfim, de risco na construção do novo, darão a base para o avanço da reforma e a superação dos hospitais psiquiátricos. O jogo nos parece dialético: essas condições sustentam a política, que, por sua vez, as sustenta. Todavia, longe está de podermos afirmar que, no caso estudado, a convivência dos dois serviços se dá de forma pacífica. Como já dissemos anteriormente, isso ocorrerá somente se o modelo da cidade não lograr nenhum avanço, tendo em vista que o avanço, segundo os entrevistados, está na operacionalização da organização do sistema de saúde mental de forma hierarquizada, ou no trabalho conjunto entre os dois serviços, ou na consideração da fala de usuários e familiares na definição das ações assistenciais. E isso indica-nos que, de fato, o avanço somente é possível se ocorrer ao lado do modelo não hospitalar. 


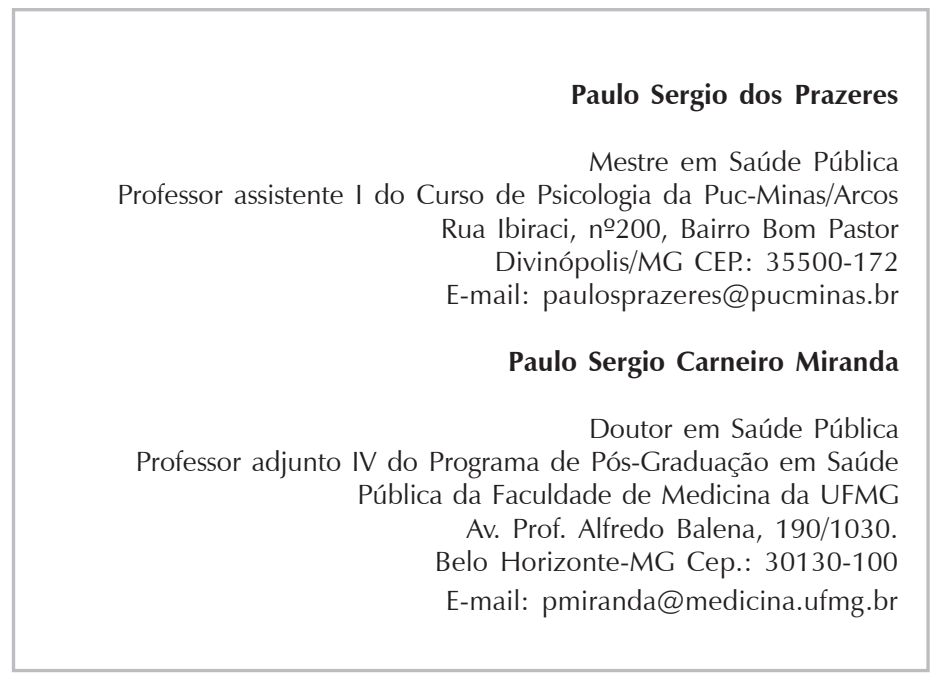

Recebido 20/04/05 Reformulado 23/08/05 Aprovado 03/11/05

BASAGLIA, Franco. As Instituições da Violência. In Basaglia, Franco. A Instituição Negada: Relato de um Hospital Psiquiátrico. 3 ed. Rio de Janeiro: Graal, 2001, pp. 99-134.

BERTOLOTE, José M. Legislação Relativa à Saúde Mental: Revisão de Algumas Experiências Internacionais. Revista de Saúde Pública, v. 29, n. 2, 1995.

CAMPOS I. Florianita Coelho Braga. Os Desafios da Gestão de Redes de Atenção em Saúde Mental para o Cuidar em Liberdade. In III Conferência Nacional de Saúde Mental: Cuidar sim, Excluir não, 8. Brasília: Conselho Nacional da Saúde, 2001, pp. 46-51.

CAMPOS II, Gastão Wagner de Souza. [Sem título]. In Fundação Hospitalar do Estado de Minas Gerais. Hospitais Psiquiátricos: Saídas para o Fim. Belo Horizonte: Gráfica da Secretaria Estadual da Saúde, 2002, pp. 59-64.
DESVIAT, Manuel. A Reforma Psiquiátrica. Rio de Janeiro: Fiocruz, 1999, $166 \mathrm{p}$.

DOR, Joel. Introdução à Leitura de Lacan: o Inconsciente Estruturado como Linguagem. 2. ed. Porto Alegre: Artes Médicas, 1991, 203 p.

MINISTÉRIO DA SAÚDE. Legislação em Saúde Mental - 19902004. 4a edição revista e atualizada, Brasília, 2004.

PASSOS, Izabel C. Friche. Desinstitucionalização em Psiquiatria: Estudo de Caso. Jornal Brasileiro de Psiquiatria, Rio de Janeiro, RJ, v. 52, n. 4, pp. 313-322, 2003.

VASCONCELOS, Eduardo Mourão. O Controle Social na Reorientação do Modelo Assistencial em Saúde Mental no Brasil Atual. In III Conferencia Nacional de Saúde Mental: Cuidar sim, Excluir não, 6. Brasília: Conselho Nacional da Saúde, 2001, pp. 32-40. 